\title{
Síntesis de la discusión de las ponencias sobre Psicología y Didáctica de las matemáticas
}

\author{
JAUME JORBA
}

Universidad Autónoma de Barcelona

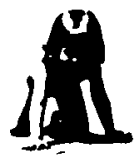

Para elaborar la síntesis de las distintas aportaciones, tanto de las ponencias como de las intervenciones en el debate posterior, al tema Psicología y Didáctica de las Matemáticas, hemos optado por una estructura que agrupase dichas aportaciones en relación a los diversos aspectos considerados por los organizadores del encuentro como los más importantes a tener en cuenta desde cada una de las áreas.

1. Las relaciones entre psicología y didáctica: estado actual de la cuestión y valoración crítica

Los Psicólogos y los Didactas constituyen actualmente dos comunidades científicas muy cerradas que, en general, ignoran las producciones mutuas. Existen unas claras representaciones cruzadas entre los dos colectivos, representaciones en las que ni los unos ni los otros se reconocen. Estas representaciones son persistentes, y se manifiestan de manera repetida.

Los Didactas recriminan básicamente a los Psicólogos un desconocimiento en profundidad de los contenidos de las áreas disciplinares, de la Historia y de la Epistemología de la Ciencia. Los Psicólogos, por su parte, imputan a los Didactas una trivialización de las teorías psicológicas del aprendizaje y una limitación formativa en este campo.

Por otro lado, los dos colectivos se interesan por el estudio de los mismos problemas, los problemas relativos a los procesos escolares de enseñanzaaprendizaje, los dos se declaran constructivistas, rechazan el aplicacionismo, consideran los contenidos como un aspecto fundamental, resaltan la importancia del contexto y la manera como influye en el proceso de cambio cognitivo, reconocen el interés de las ideas previas, «missconceptions», en la construcción del conocimiento, etcétera.

Puede decirse que Psicología y Didáctica son dos maneras de mirar los mismos problemas y que por tanto se complementan y necesitan mutuamente.

Correspondencia con autor: Universidad Autónoma de Barcelona. Bellaterra. 08193 Barcelona. 


\section{6}

Pero a pesar de las tendencias e indicadores que apuntan hacia una convergencia, ésta es más formal que real, quizás provocada por el hecho de que Psicología y Didáctica son administrativamente áreas de conocimiento diferentes con especificaciones y campos de actuación propios. El pertenecer a una o a otra área determina de hecho una cierta desconfianza y prevención hacia la otra.

Es también interesante señalar que este desconocimiento y falta de relación se da también entre diferentes Didácticas específicas.

\section{La especificidad del conocimiento didáctico y del conocimiento psicológico}

Puede decirse que la Didáctica y la Psicología proporcionan dos formas distintas de mirar y estudiar los mismos problemas, tal vez con objetivos, marcos teóricos de referencia, metodologías de investigación, procedimientos de intervención, etc., diferentes.

Así, y citando textualmente una de las ponencias, en particular la Didáctica de las Matemáticas tiene por objeto el estudio del aprendizaje y de la enseñanza de las matemáticas. El didacta elabora un conocimiento a enseñar desde un saber disciplinar. $\mathrm{El}$ «saber a enseñar» que surge de esta transposición didáctica es un producto diferente del saber disciplinar, es un saber de naturaleza didáctica.

Pero, aunque el didacta se interesa por el proceso de enseñar, igualmente se interesa por el del aprendizaje, ya que ambos se dan íntimamente relacionados en el aula. Por tanto, ningún producto didáctico surge al margen de las teorías psicológicas que explican el comportamiento inteligente del ser humano, su estructura y su génesis, ni del proyecto educativo que preside un currículum concreto.

Pero la Didáctica no tiene como única fuente la Psicología, sino muchas otras áreas de conocimienta. El conjunto de preguntas a las que trata de dar respuesta la Didáctica de las Matemáticas remite a diferentes áreas de conocimiento:

- La materia científica que se quiere enseñar con su estructura específica.

- La Historia y Epistemología de la Ciencia.

- La Sociología.

- La Lingǘstica.

- La Pedagogía, etcétera.

Además, dado el carácter profesional de la Didáctica, este carácter la liga a la práctica docente y a los problemas con los que se encuentran los profesores de Matemáticas en el aula.

\section{3 y 4 . Aportaciones reales y/o potenciales de la reflexión y el conocimiento} didáctico a la teoría, la investigación y la intervención psicológicas, y viceversa

La evolución y desarrollo de los planteamientos didácticos en la educación matemática han estado, durante las últimas décadas, claramente influenciados por la Psicología.

Cabe remarcar la influencia de la corriente conductista, del enfoque estructuralista y formativo, y actualmente del constructivismo.

Estas corrientes han marcado, y marcan, las tendencias que se apuntan en las líneas de investigación en psicología de la educación matemática. Se puede hablar de cuatro líneas que conforman el presente y el futuro inmediato de la psicología en educación mạtemática: 
- La aproximación constructivista.

- Los estudios basados en la inteligencia artificial.

- Las relaciones entre los aspectos formales, algoritmos e intuiciones de la actividad matemática.

- Los problemas relacionados con la metacognición.

Existen muchos modelos que se usan en la investigación de los procesos cognitivos implícitos en el aprendizaje de los conceptos matemáticos:

- Imagen conceptual y visualización.

- Esquema conceptual y definición conceptual.

- Conceptos y concepciones.

- Teoría de los campos conceptuales.

- Los modelos de la inteligencia artificial.

También existen diversas líneas de investigación dedicadas a los aspectos sociales y psicológicos sobre lo que podríamos llamar «comportarse como un matemático". Tratan cuestiones generales como la resolución de problemas: definir, hacer conjeturas, probar. Se trata de habilidades que todo matemático domina pero que en general no se enseñan ni consciente ni explícitamente y en las que entran consideraciones tan difíciles de definir como elegancia, originalidad, creatividad y estética.

Las investigaciones que se ocupan de la dimensión social, relacional e institucional de los procesos escolares de enseñanza aprendizaje muestran la importancia del contexto y de la situación en estos procesos. Estas investigaciones ponen de manifiesto que el enfoque cognitivo debe ser complementado con el social si se quiere conocer cómo se produce el cambio cognitivo y cuáles son los mecanismos de influencia educativa que hacen que el alumno aprenda.

Por otro lado las matemáticas, quizás más que ninguna otra disciplina, ha aportado un contenido fácil de estudiar y atractivo para los psicólogos interesados por la enseñanza, ya que poseen una estructura muy organizada, su contenido es autosuficiente y está bien delimitado, etc. Ello ha provocado que un gran número de psicólogos hayan orientado su investigación hacia el estudio de los procesos de adquisición de conocimientos matemáticos. Y ello tanto si estaban interesados en el estudio de los procesos de aprendizaje en contenidos específicos, como en los procesos más generales de pensamiento.

5. Divergencias $y / o$ desencuentros manifiestos -en cuanto a enfoques, objetivos, marcos teóricos de referencia, metodología de investigación, procedimientos de intervención, etc. - entre psicología y didáctica

Respecto a esta cuestión, las posibles divergencias y/o faltas de convergencia parecen más bien provocadas por consideraciones técnico-administrativas, por ser consideradas Psicología y Didáctica áreas de conocimiento diferentes, y por la función que, históricamente, cada una de estas disciplinas ha jugado con relación a la otra; que no por el objeto de estudio y los objetivos que persiguen.

Así, la Psicología, desde presupuestos más o menos generales sobre el funcionamiento de la mente y el aprendizaje, ha pretendido ser prescriptiva con respecto a la forma en que deben desarrollarse los procesos de enseñanzaaprendizaje. Al centrarse más en el cómo enseñar que en el qué, no consideraba suficientemente la importancia de conocer el contenido de la disciplina.

En cambio, la Didáctica al estar vinculada a la acción y a la necesidad de conseguir resultados inmediatos ha generado técnicas y recursos no siempre fun- 


\section{8}

damentados teóricamente. Así a falta de un marco teórico propio, realizaba una transposición directa de los principios teóricos y de los instrumentos metodológicos de otras disciplinas a la práctica de aula. Dado que estas disciplinas no aportaban, en general, elementos específicos de orientación para la enseñanza, dichos principios constituían muchas veces un marco superestructural, superpuesto y desvinculado de la práctica, que se guiaba más por la intuición y la experiencia acumulada.

En el momento actual, en el caso de las matemáticas, las anteriores consideraciones quizás ya no son completamente válidas, pues por un lado la investigación psicológica sobre los procesos de aprendizaje se ha orientado hacia el estudio de dichos procesos en dominios o áreas de conocimiento específicos, y por otro, existe un notable incremento de la investigación didáctica con voluntad de fundamentación teórica.

Así, psicólogos y didactas, por separado o conjuntamente, se han puesto a investigar en líneas semejantes. Es de remarcar la aportación desde ambos campos sobre las ideas previas del alumnado, las concepciones alternativas, «misconceptions» etcétera.

Sin embargo, subsiste todavía una fuerte divergencia en los enfoques de psicólogos y didactas, aunque comiencen a no existir razones teóricas de fondo que lo justifiquen.

A pesar de todo ello, es importante considerar que la falta de convergencia y la desconfianza mutua es un hecho que no se debe olvidar si quiere conseguirse una futura convergencia y colaboración.

\section{Parámetros que deberían presidir las relaciones entre didáctica y psicología, y posibles líneas de colaboración}

Si bien actualmente se ha producido un proceso de aproximación entre Psicología y Didáctica ya que ambas disciplinas tienen un objeto de estudio común: los procesos escolares de enseñanza-aprendizaje en contenidos específicos dentro de un enfoque constructivista, también se puede señalar que dicha aproximación no ha resuelto uno de los problemas fundamentales: cómo se produce el cambio conceptual en el alumno en las situaciones de enseñanza y aprendizaje. Una de las razones puede ser el hecho de que sigue habiendo una cierta transposición de los planteamientos de la psicología a los estudios que se interesan por dichos procesos.

Una posible vía de aproximación entre Didáctica y Psicología de la Educación matemática, podría ser la de construir un marco de referencia teóricopráctico propio que se oriente hacia el estudio de los procesos escolares de enseñanza-aprendizaje, como procesos de construcción social del saber.

Este enfoque exige:

- Que se aborden los estudios y trabajos de investigación desde una perspectiva no meramente individual, sino que preste atención a la influencia del contexto sobre cada individuo. Es decir, aceptar que la unidad de análisis más útil no es el individuo sino la persona en su contexto de actividad: la escuela.

- Que se tenga en cuenta que el cambio cognitivo viene posibilitado por la actividad constructiva, y que ésta se da en el proceso de interacción en el aula entre profesor-alumno-contenidos, y no tan sólo en los procesos internos del alumno. 
- Estudiar los mecanismos de influencia educativa que permiten al alumno pasar de unas matemáticas intuitivas a unas matemáticas formales, y por los mecanismos que permiten que estas matemáticas formales se puedan vincular a sus significados referenciales, pasando a ser usadas significativamente.

De esta forma, completando el enfoque cognitivo con el social, es posible que el constructivismo compartido entre psicólogos y didactas empiece a funcionar.

Estas consideraciones y las de los apartados anteriores parecen reclamar la formación de equipos integrados de psicólogos de la educación y didactas que colaboren en el estudio de problemas comunes, que interesen a los dos colectivos, que les permitan abordar algunos de los problemas fundamentales relativos a los procesos escolares de enseñanza-aprendizaje.

Las posibles líneas de colaboración pueden estar centradas en:

- la aproximación constructivista,

- los estudios basados en la inteligencia artificial,

- las relaciones entre los aspectos formales, algoritmos e intuiciones de la actividad matemática,

- los problemas relacionados con las metacognición,

- la dimensión social, relacional e institucional del proceso de enseñanza aprendizaje.

Finalmente, es fundamental no olvidar la utilidad de la investigación didáctica. El receptor final debería ser el profesorado que está en el aula. 